\title{
Conformational Analysis and Electronic Structure of Chiral Carbon and Carbon Nitride Nanotubes
}

\author{
Cristiano Geraldo de Faria, Mariza Grassi, Ana Claudia Monteiro Carvalho* \\ Grupo de Desenvolvimento de Estruturas Nanométricas e Materiais Biocompatíveis - GDENB, \\ Departamento de Física e Química, Instituto de Ciências Exatas - ICE, \\ Universidade Federal de Itajubá - UNIFEI, CEP 37.500-930, Itajubá, MG, Brazil
}

Received: September 15, 2010; Revised: August 2, 2011

\begin{abstract}
Geometry and electronic structure of chiral carbon and carbon nitride $(\mathrm{CNx})$ nanotubes were investigated through quantum chemical methods. Finite nanotubes with diameters ranging from 5 to $10 \AA$ and containing up to 500 atoms were considered. CNx structures were built through random substitution of carbon atoms by nitrogen. The molecules were fully optimized by semi-empirical quantum chemical method (PM3). Our results show that the energy associated with nitrogen incorporation depends strongly upon the tube helicity and diameter. The doping of nanotubes with nitrogen contributes to reduce the stress caused by the small diameter of the studied systems. Density of States (DOS) results for pure carbon and CNx nanostructures, obtained through DFT and Hartree-Fock calculations, were analyzed. The introduction of nitrogen in the tube produce states in the gap region which characterizes the metallic behavior, as expected for these systems after N-doping.
\end{abstract}

Keywords: chiral nanotubes, nitrogen, PM3, DFT

\section{Introduction}

Since their discovery by Sumio Iijima ${ }^{1}$ in 1991 , carbon nanotubes (CNT) have been intensively investigated, both theoretically and experimentally, due to their outstanding electronic and mechanical properties. These systems are usually treated as one-dimensional semiconductors or metals, depending on the geometry of the tubes ${ }^{2}$. The classification of single walled carbon nanotubes (SWNTs) is based on two chiral indices $(n, m)$ which give the geometry of the basic graphene ribbon that is rolled to form a nanotube. According to the usual nomenclature, nanotubes are said to be achiral when one of the indices is zero (zig-zag) or when $\mathrm{n}=\mathrm{m}$ (armchair) and all the others are chiral. It has been proposed that CNTs behave as 1-D conductors when the difference between the chiral indices is a multiple of $3: \mathrm{n}-\mathrm{m}=3 \mathrm{q}$, where $\mathrm{q}$ is an integer ${ }^{2}$.

Semiconducting nanotubes are of interest in the fabrication of electronic devices as they combine the outstanding mechanical properties of small band gap semiconductors, altogether in systems of nanoscopic dimensions. Metallic nanotubes are interesting as well since they are prototypes of mechanically robust molecular wires. The development of experimental techniques that precisely synthesize carbon nanotubes with uniform helicity and electronic properties is still a challenge. This fact might impose great limitations on the technological applications of these nanostructures. Theoretical ${ }^{3}$ and experimental ${ }^{4-6}$ studies have shown that is possible to modify the electronic properties of the nanotubes by replacing some of carbon atoms with heteroatoms ${ }^{7}$. Futhermore the incorporation of these heteroatoms also changes the nanotube estructure ${ }^{8,9}$, chemical reactivity ${ }^{10}$ and mechanical properties ${ }^{11}$, presenting the possibility of controlling nanotube properties. In recent years, various synthesis methods to produce $\mathrm{CNx}$ nanotubes have been reported, including chemical vapor deposition (CVD) ${ }^{12-14}$, arc discharging ${ }^{15,16}$, laser vaporization ${ }^{17}$, catalytic pyrolysis ${ }^{18-21}$, ion implantation ${ }^{22}$, and others. Quantum chemical calculations of the structural stability and electronic properties carbon-nitride systems have been reported by several authors ${ }^{4,23-27}$.

In our previous work ${ }^{15,28}$, simulations of a random doping of CNTs showed that substitutional nitrogen on the hexagonal carbon network produces localized distortions on the tube walls. Analyzing nitrogen incorporation energy results for molecules of similar diameter, we conclude that carbon atoms are more easily substituted by nitrogen atoms in zigzag than in armchair nanotubes.

In the present work we report a quantum chemical study on chiral nanotubes with diameters varying from 5 to $10 \AA$. We analyze the role played by nitrogen doping in the stabilization of these molecular systems. In the case of chiral nanotubes our theoretical results showed that the energies of nitrogen incorporation are close to the calculated for armchair nanotubes regardless of its helicity. The modifications in the electronic structure due to random nitrogen substitution are also analyzed. A band associated with donor states emerges below the bottom of the conduction band after doping.

\section{Computational Details}

The geometry of tubular structures composed by carbon and nitrogen containing form 100 to 500 atoms were fully optimized through the semi-empirical quantum chemical method Parametric Method 3 (PM3) ${ }^{29}$. PM3 is a semi-empirical method derived from the Hartree-Fock theory. The advantages of semiempirical calculations are that they are much faster than ab initio calculations, and can be used for large organic molecules. The disadvantage of semiempirical calculations is that some properties cannot be predicted reliably. In the case of the properties analyzed in this study, PM3 semiempirical 
method is very reliable to predict molecular geometries and heats of formation of carbon materials. PM3 error in heats of formation is about $8.0 \mathrm{kcal} . \mathrm{mol}^{-1[30]}$, with respect to the experimental values. Average error in bond length is $0.05 \AA^{[30]}$.

Terminal bonds at tube ends were saturated with hydrogen atoms. Chiral nanotubes were then nitrogen-doped and the geometries were re-optimized. Nitrogen atoms were randomly placed substituting carbons at a given concentrations. For these substitutions, we adopted the following criteria: (i) adjacent atoms should not be substituted; (ii) the substitution of even number of atoms is preferable because a closed shell system is formed.

The energy associated to nitrogen incorporation was calculated as the difference in formation enthalpy of $\mathrm{N}$-doped and pure carbon systems divided by the number of nitrogens. These calculations were performed within the quantum chemical package GAMESS ${ }^{31}$.

The electronic structure of the optimized tubular molecules was obtained through Hartree-Fock theory adopting CEP-4G basis set and the functional BLYP in the 6-31G basis set as implemented in GAUSSIAN03 package ${ }^{32}$. Becke' ${ }^{33}$ exchange functional along with the correlation functional of Lee, Yang, and $\operatorname{Parr}^{34}$ (BLYP) has been used successful in the electronic properties calculations of carbon nanotubes. However, this functional has been shown to be not allowed to large systems as some model molecules analyzed in this work. The Compact Effective Potencial (CEP) proposed by Stevens and co-workers in $1984^{[35]}$ is a pseudo-orbital basis set which consists of four Gaussian primitives using a common set of exponents for the $\mathrm{s}$ and $\mathrm{p}$ functions. Comparing with complete basis sets, these core potentials for the first- and second-row atoms ${ }^{35}$ showed good results for electronic properties on large molecules. Density of States was convoluted using Gaussian line shapes with a half-width broadening of $0.2 \mathrm{eV}$. The DOS profiles were used for the interpretation of the structure evolution upon $\mathrm{N}$ doping of chiral carbon nanotubes.

\section{Results and Discussions}

\subsection{Structural properties and enthalpy of formation}

In Figure 1 the geometries of the chiral nanotubes considered in the present study are schematically shown. These corresponds to the optimized conformations of tubes (5.3), (6.3), (6.4), (7.4), (8.5), and (9.3), which have diameters from 5 to $9 \AA$.

The random substitution of carbon by nitrogen atoms produces geometry distortions around the nitrogen atoms and become more important as more nitrogen atoms are incorporated, transforming the straight tube walls into corrugated walls (Figure 2). As can be observed in Figure 1, before doping the model molecules do not show irregularities along the tube walls. Similar results were already obtained in our early works ${ }^{28,36}$. In these works ${ }^{28,36}$ we showed that $\mathrm{N}$-doped zig-zag tubes are more stable (the formation enthalpy decreases) than armchair tubes of similar diameter. At the same time the stressed small diameter tubes are more easily doped by nitrogen than the large diameter tubes.

In Figure 3 we show the evolution of the enthalpy associated in nitrogen incorporation as a function of the $[\mathrm{N}] /[\mathrm{C}]$ concentration for chiral and achiral carbon nitride nanotubes. The enthalpy of incorporation was calculated as the relative enthalpy per added nitrogen $\left(\left[\Delta \mathrm{H}_{\mathrm{f}}\left(\mathrm{C}_{\mathrm{n}-\mathrm{x}} \mathrm{N}_{\mathrm{x}}\right)-\Delta \mathrm{H}_{\mathrm{f}}\left(\mathrm{C}_{\mathrm{n}}\right)\right] / \mathrm{x}\right)$, where $\Delta \mathrm{H}_{\mathrm{f}}$ is the heat of formation obtained from PM3 calculations. Full square symbols in this picture indicate the results for armchair nanotubes, and full cycle symbols are for zig-zag nanotubes. Open symbols are for chiral nanotubes. Analyzing the energy of incorporation of nitrogen in the chiral nanotubes studied, we conclude that nanotubes with small diameters are more easily doped by nitrogen than the large ones.
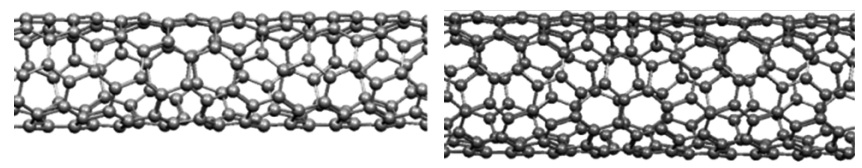

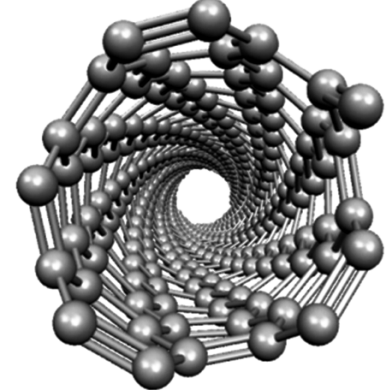

(a)
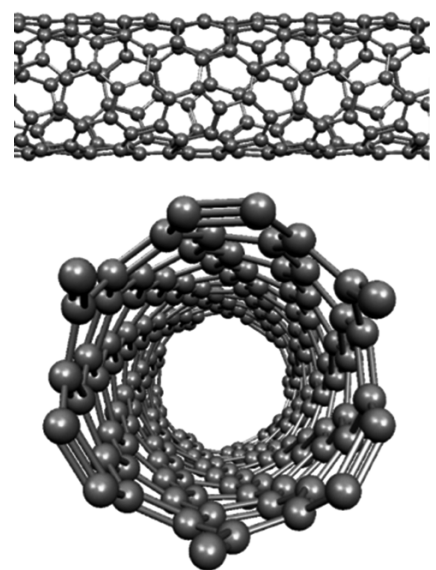

(b)
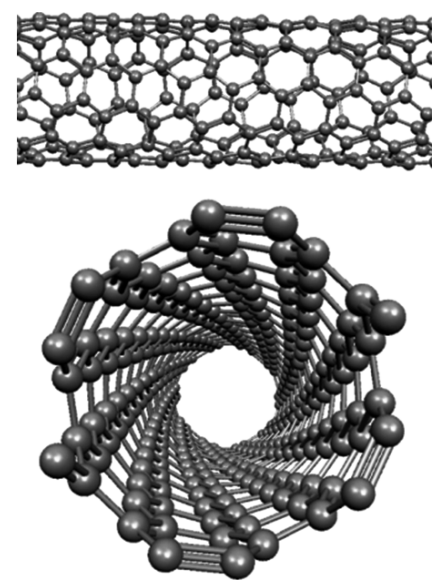

(c)

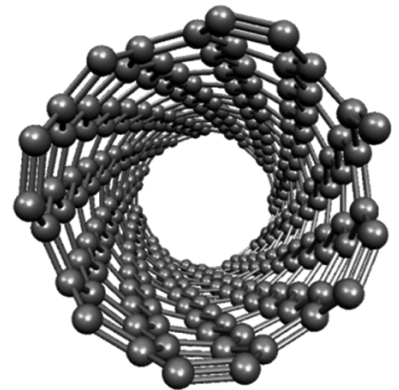

(d)
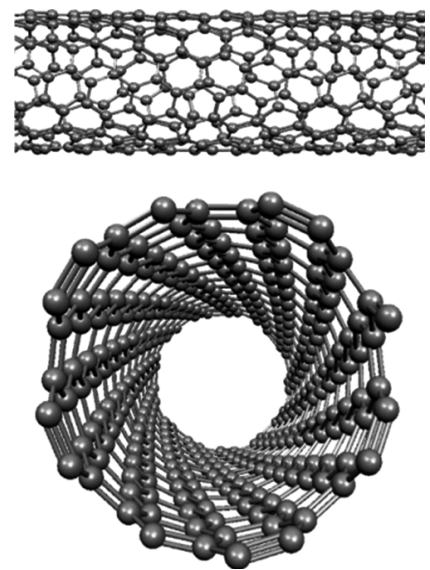

(e)
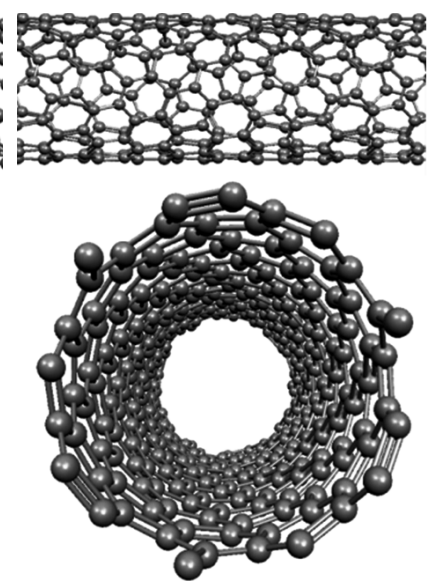

(f)
Figure 1. Fully relaxed nanotubes studied in this work: a) nanotube (5.3); b) nanotube $(6.3)$; c) nanotube $(6.4)$; d) nanotube $(7.4)$; e) nanotube $(8.5)$; and f) nanotube (9.3).

Moreover, comparing zigzag, armchair, and chiral nanotubes our theoretical results showed that the enthalpy of formation for $\mathrm{N}$-doped chiral nanotubes is similar to the armchair nanotubes, independently of their helicity.

Based on the results obtained for relative enthalpy of formation, we concluded that the energy associated to incorporation of nitrogen depends on the tubes diameter and helicity for both chiral and achiral carbon nitride nanotubes. 


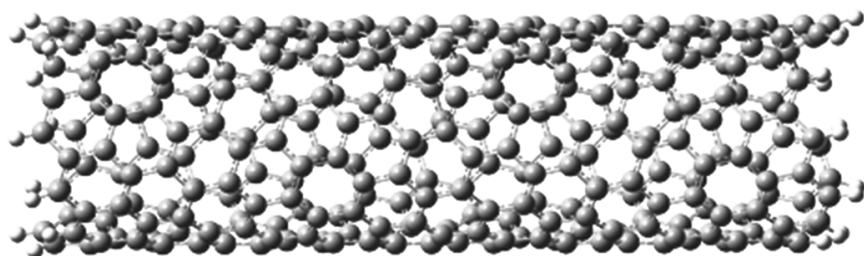

(a)

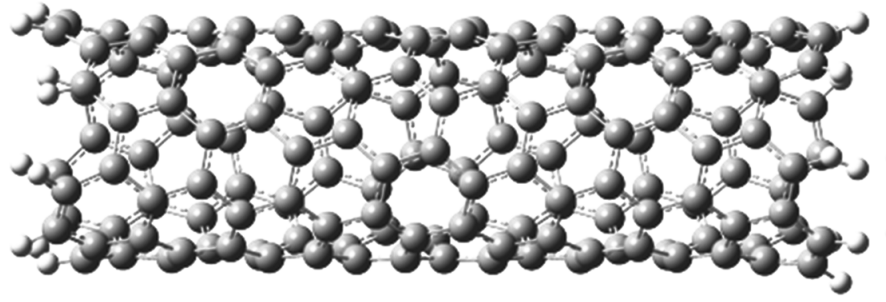

(c)

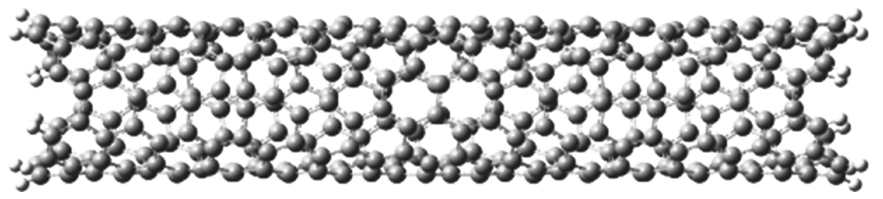

(e)

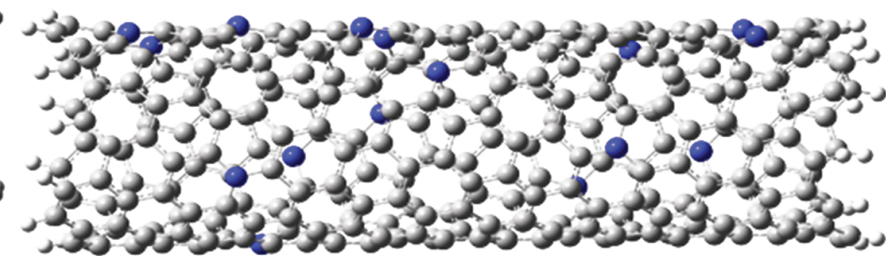

(b)

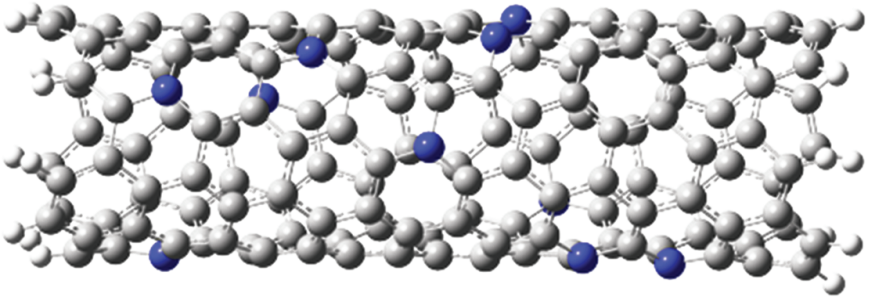

(d)

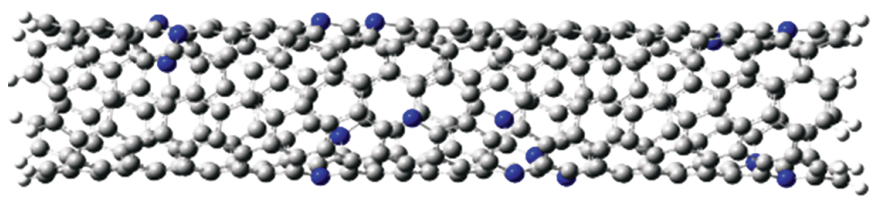

(f)

Figure 2. Fully relaxed nanotubes calculated after N-doping: a) tube $(6.3)$; b) tube $(6.3)$ with $(\mathrm{N}) /(\mathrm{C})=5 \%$; $)$ tube $(6.4)$; d $)$ tube $(6.4)$ with $(\mathrm{N}) /(\mathrm{C})=5 \%$; e) tube (9.3); and f) tube $(9.3)$ with $(\mathrm{N}) /(\mathrm{C})=5 \%$. In this picture, carbon atoms are in gray, nitrogen atoms are in blue, and hydrogen atoms are in white.

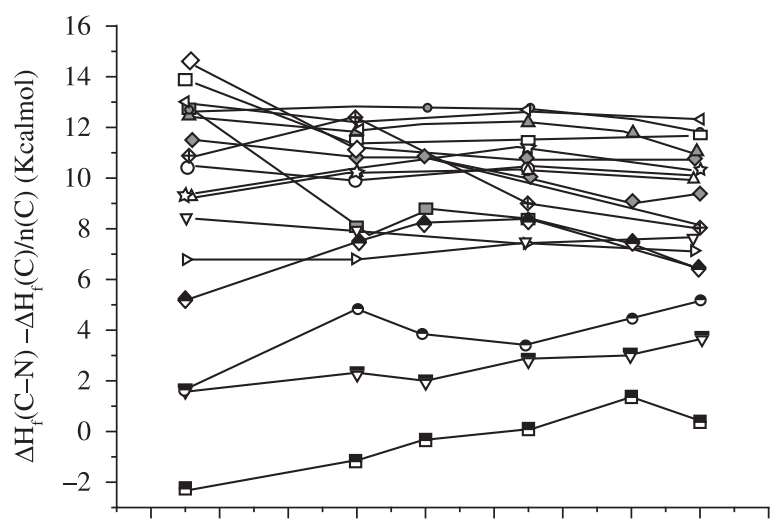

$\begin{array}{llllllllll}0.04 & 0.06 & 0.08 & 0.10 & 0.12 & 0.14 & 0.16 & 0.18 & 0.20 & 0.22\end{array}$

$[\mathrm{N}] /[\mathrm{C}]$

\begin{tabular}{|c|c|c|c|}
\hline$\rightarrow-$ Tube (4.4) & $\prec$ Tube $(5.5)$ & $\triangle-$ Tube $(6.6)$ & -ం- Tube (8.8) \\
\hline$\square$ Tube (6.0) & $\rightarrow$ Tube $(8.0)$ & $\rightarrow$ Tube (9.0) & $\multimap$ Tube (10.0) \\
\hline$\multimap$ Tube (4.3) & $\rightarrow$ Tube (5.3) & $\rightarrow$ Tube (6.3) & - Tube (6.4) \\
\hline$\diamond-$ Tube $(7.4)$ & $\leadsto$ Tube (8.4) & $\square$ Tube (8.5) & $\triangle-$ Tube (9.3) \\
\hline$\dashv$ Tube $(9.6)$ & & & \\
\hline
\end{tabular}

Figure 3. Heats of formation $\left(\Delta \mathrm{H}_{\mathrm{f}}\right)$ obtained from PM3 calculations as a function of the $[\mathrm{N}] /[\mathrm{C}]$ concentration, for $\mathrm{CN}$ cluster and several carbon nitride nanotubes. Results of PM3 calculations show that the energy associated with nitrogen incorporation depends strongly upon the tube helicity and diameter. Nanotubes with lower diameter are more stabilized by nitrogen incorporation.

\section{Electronic Properties}

The doping of carbon nanotubes with nitrogen atoms is a practical and effective way to tailor their electronic properties. Incorporation of nitrogen atoms on carbon nanotubes changes the electrical properties and chemical reactivity of carbon nanotubes ${ }^{37,38}$. Nitrogendoped carbon nanotubes render them n-type material regardless of tube chirality ${ }^{39}$, and nitrogen in doped carbon nanotubes acts as a donor. In particular, nitrogen-doped carbon nanotubes are effective field emitters ${ }^{40-43}$. $\mathrm{CNx}$ nanotubes have been demonstrated to show lower turn-on and higher current density than undoped carbon nanotubes ${ }^{42}$. Incorporation of nitrogen atoms on carbon nanotubes changes their tubular structures. Simulations of a random doping of carbon nanotubes showed that substitutional nitrogen on the hexagonal carbon network produces localized distortions on the tube walls. However, the corrugation does not produce the bends needed to interpret the bamboo-like structure that are experimentally observed. Y-junction can be created introducing defects in the hexagonal network of bonds ${ }^{35,36}$. Theoretical studies have proposed different types of defects in $\mathrm{CNx}$ nanostructures as, for example: (i) odd-membered rings $s^{44-46}$, and (ii) vacancies, as pyridine-like $\mathrm{e}^{47,48}$, and porphyin-like ${ }^{49}$ structures. Like unbranched nanotubes, the Y-junction ${ }^{50} \mathrm{CNx}$ nanotube is also considered to be one of the very promising materials in the upcoming field of nanoelectronics. Although a number of theoretical and experimental studies have been carried out on the electronic and structural properties of carbon nitride nanotubes, some issues are not clear, such as the electronic properties dependence as a function of the concentration and distribution of nitrogen in N-doped nanostructures.

In this study, PM3 optimized geometries of carbon and $\mathrm{CNx}$ nanotubes were used as input for electronic properties calculations at the HF/CEP-4G and BLYP/6-31G level of theory. Results of density of states (DOS) obtained by BLYP functional are displayed in Figure 4a for chiral nanotube (6.3). Calculations of electronic properties on DFT level of theory showed to be not allowed to large molecules analyzed, as (5.3), (6.4), (8.5), (9.3) and (9.6) nanotubes. In this sense, it was recalculated the electronic properties of small diameter nanotubes using HF/CEP-4G level of theory and compared with previous results in DFT level theory. CEP-4G basis gave 


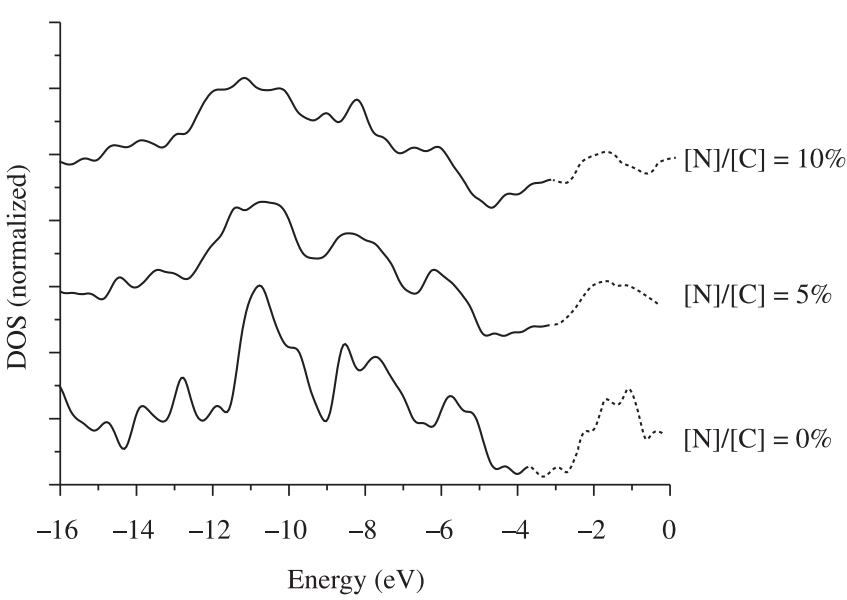

(a)

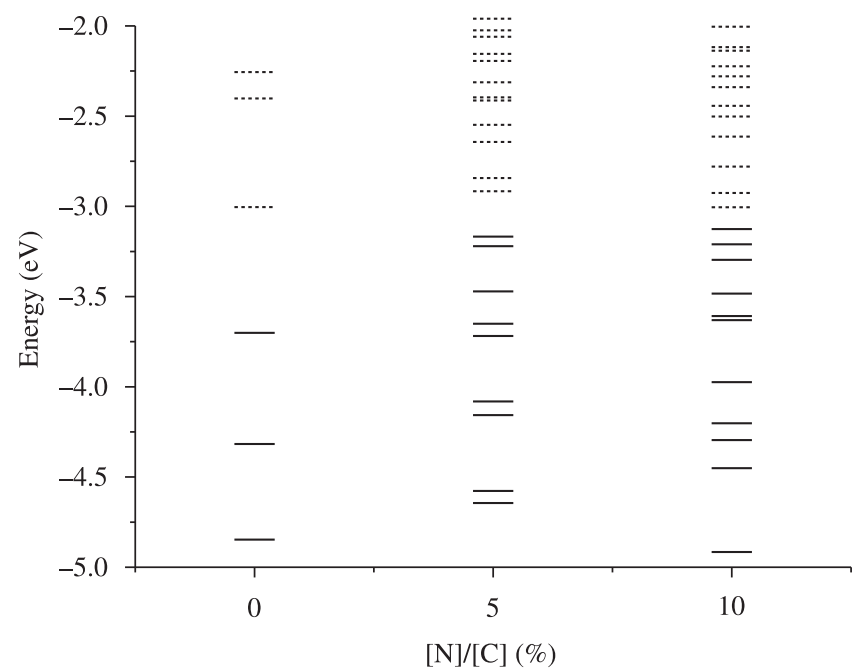

(b)

Figure 4. Evolution of DOS for nanotube (6.3). In the case of doped nanostructures the increase of nitrogen modifies the $\pi$ bands. At right, is showed an inset of the gap region for different nitrogen concentration. This results show the metallic behavior of chiral nanotubes after doping.

electronic properties in qualitative good agreement with the results of more accurate method for small diameter nanotubes. In this study, $\mathrm{HF} / \mathrm{CEP}-4 \mathrm{G}$ basis was used to determinate the electronic properties of large model molecules.

Results of density of states calculations are shown in Figure 4a for carbon nanotubes and carbon nitride nanotubes. In Figure 4a, the curve below represents the DOS of chiral carbon nanotube. The other curves are related to carbon nitride nanotubes with some selected nitrogen $(\mathrm{N}) /(\mathrm{C})$ concentration. The introduction of nitrogen in chiral tubes results: (i) a new peak in the top of the valence band. This structure is associated to the nitrogen incorporation which contributes with a pair of electrons; (ii) the main peak is continuously shifted toward lower energies as more nitrogen content is increased. In Figure 4b, we show an inset of the density of states in the gap region for (6.3) chiral nanotube. This picture shows the last highest occupied molecular orbitals (HOMO) and the first lowest unoccupied molecular orbitals (LUMO) for (6.3) carbon and carbon nitride nanotube. Results for frontier orbitals energy using HF or DFT methods, to the all chiral and achiral nanotubes studied, resulted in the decreasing of HOMO-LUMO gap after nitrogen substitution. This indicates that the introduction of nitrogen in the tube produces states in the gap region which characterizes the metallic behavior, as expected for these nanostructures after N-doping.

\section{Conclusions}

In summary, we have presented structural and electronic properties calculations of nanotubes of differente chirallity. Results of enthalpy of formation for chiral nanotubes showed that small diameter structures are more easily doped by nitrogen than large diameter tubes. Structural stress caused due to effects of curvature is reduced by the nitrogen incorporation, which contributes to the energy stabilization of small diameter tubes. Comparing the results of heat of formation for zigzag, armchair and chiral carbon nitride nanotubes we concluded that the energy associated to incorporation of nitrogen depends of the tubes diameter and chirality.

Calculations based on HF and DFT methods demonstrate that the introduction of nitrogen generates new states in the gap region characterizing the metallic behavior, as expected for $\mathrm{CNx}$ nanotubes.

\section{Acknowledgements}

The authors thank the computational support from Centro Nacional de Computação de Alto Desempenho - CENAPAD. This work was supported by the brazilian agency Fundação de Apoio à Pesquisa de Minas Gerais - FAPEMIG. The author C. G. de Faria, thanks the financial support from Fundação de Pesquisa e Assessoramento à Indústria - FUPAI.

\section{References}

1. Iijima S. Helical microtubules of graphitic carbon. Nature. 1991; 354:56-58. http://dx.doi.org/10.1038/354056a0

2. Saito R, Dresselhaus G and Dresselhaus MS. Physical Properties of Carbon Nanotubes. London: Imperial College Press; 1998.

3. Latil S, Roche S, Mayou D and Charlier J-C. Mesoscopic transport in chemically doped carbon nanotubes. Physical Review Letters. 2004; 92(25):256805-9. http://dx.doi.org/10.1103/PhysRevLett.92.256805

4. Terrones M, Ajayan PM, Banhart F, Blase X, Carroll DL, Charlier JC et al. $\mathrm{N}$-doping and coalescence of carbon nanotubes: síntesis and electronic properties. Applied Physics A: Materials Science \& Processing. 2002; 74:355-361. http://dx.doi.org/10.1007/s003390201278

5. Hsu WK, Chu SY, Muñoz-Picone E, Boldú JL, Firth S, Franchi Pet al. Mettalic behavior of boron-containing carbon nanotubes. Chemical Physics Letters. 2000; 323:572-579. http://dx.doi.org/10.1016/S0009-2614(00)00553-4

6. Golberg D, Dorozhkin PS, Bando Y, Dong Z-C, Tang CC, Uemura Y et al. Structure, transport and field-emission properties of compound nanotubes: $\mathrm{CNx}$ vs BNCx $(\mathrm{x}<0.1)$. Applied Physics A: Materials Science \& Processing. 2003; 76:499-507. http://dx.doi.org/10.1007/s00339-002-2047-7

7. Terrones M, Jorio A, Endo M, Rao AM, Kim YA, Hayashi T et al. New directions in nanotube science. Materials Today. 2004; 7:30-45. http://dx.doi. org/10.1016/S1369-7021(04)00447-X

8. Nemes-Incze P, Daróczi N, Sárközi Z, Koós AA, Kertész K, Tiprigan O et al. Syntesis of bamboo-structured multiwalled carbon nanotubes by spray pyrolysis method, using a misture of benzene and pyridine. Journal of Optoelectronics and Advanced Materials. 2007; 9:1525-1529.

9. Reyes-Reyes M, Grobert N, Kamalakaran R, Seeger T, Golberg D, Rühle M et al. Efficient encapsulation of gaseous nitrogen incide carbon nanotubes with bamboo-like structure using aerosol thermolysis. Chemical Physics Letters. 2004; 396:167-173. http://dx.doi.org/10.1016/j.cplett.2004.07.125

10. Nevidomsky A, Csányi G and Payne MC. Chemically active substitutional nitrogen in impurity in carbon nanotubes. Physical Review Letters. 2003; 91:105502(1-4). http://dx.doi.org/10.1103/PhysRevLett.91.105502 
11. Hernandez E, Goze C, Bernier P and Rubio A et al. Elastic properties of single-wall nanotubes. Applied Physics A: Materials Science \& Processing. 1999; 68:287-292. http://dx.doi.org/10.1007/s003390050890

12. Ayala P, Freire Junior FL, Rümmeli MH, Grüneis A, Pichler T. Chemical vapour deposition of functionalized single-walled carbon nanotubes with defined nitrogen doping. Physica Status Solidi B. 2007; 244:4051-4055. http://dx.doi.org/10.1002/pssb.200776180

13. Tang C, Bandoa Y, Golberga D and Xu F et al. Structure and nitrogen incorporation of carbon nanotubes synthesized by catalytic pyrolysis of dimethylformamide. Carbon. 2004; 42:2625-2633. http://dx.doi.org/10.1016/j. carbon.2004.05.047

14. Koós AA, Dowling M, Jurkschat K, Crossley A and Grobert N. Effect of the experimental parameters on the structure of nitrogen-doped carbon nanotubes produces by aerosol chemical vapour deposition. Carbon. 2009; 47:30-37. http://dx.doi.org/10.1016/j.carbon.2008.08.014

15. Droppa Junior R, Hammer P, Carvalho ACM, Dos Santos MC and Alvarez F. Incorporation of nitrogen in carbon nanotubes. Journal of NonCrystalline Solids. 2002; 299-302:874-879. http://dx.doi.org/10.1016/S00223093(01)01114-0

16. Glerup M, Steinmetz J, Samaille D, Stéphan O, Enouz S, Loiseau A et al. Synthesis of N-doped SWNT using the arc-discharge procedure. Chemical Physics Letters. 2004; 387:193-197. http://dx.doi.org/10.1016/j. cplett.2004.02.005

17. Lin H, Arenal R, Enouz-Vedrenne S, Stephan O and Loiseau A. Nitrogen configuration in individual CNx-SWNTs synthesized by laser vaporization technique. Journal of Physical Chemistry C. 2009; 113:9509-9511. http://dx.doi.org/10.1021/jp902478j

18. Lee CJ, Lyu SC, Kim H-W, Lee JH and Cho KI. Synthesis of bamboo-shaped carbon-nitride nanotubes using $\mathrm{C}_{2} \mathrm{H}_{2}-\mathrm{NH}_{3}-\mathrm{Fe}(\mathrm{CO})_{5}$ system. Chemical Physics Letters. 2002; 359:115-120. http://dx.doi.org/10.1016/S0009-2614(02)00655-3

19. Jang JW, Lee CE, Lyu SC, Lee TJ and Lee CJ. Structural study of nitrogendoping effects in bamboo-shaped multiwalled carbon nanotubes. Applied Physics Letters. 2004; 84:2877-2879. http://dx.doi.org/10.1063/1.1697624

20. Han WQ, Kohler-Redlich P, Seeger T, Ernst F, Rühle M, Grobert N et al. Aligned $\mathrm{CNx}$ nanotubes by pyrolysis of ferrocene/ $\mathrm{C}_{60}$ under $\mathrm{NH}_{3}$ atmosphere. Applied Physics Letters. 2000; 77:1807-1809. http://dx.doi. org/10.1063/1.1311813

21. Liu J, Webster S and Carroll DL. Temperature and flow rate of $\mathrm{NH}_{3}$ effects on nitrogen content and doping environments of carbon nanotubes growth by injection CVD method. Journal of Physical Chemistry B. 2005; 109:15769-15774. http://dx.doi.org/10.1021/jp050123b

22. Yamamoto K, Takafumi K and Kazuhiko M. Nitrogen doping of single-walled carbon nanotube by using mass-separated low-energy ion beams. Japanese Journal of Applied Physics. 2005; 44:1611-1614. http://dx.doi.org/10.1143/ JJAP.44.1611

23. Zhao J-X, Ding Y, Wang X-G, Cai Q-H and Wang X-Z. Theoretical studies of the CNx nanotube with four-nitrogen divacancy (4ND) defects. Diamond and Related Materials. 2011; 20:36-41. http://dx.doi.org/10.1016/j. diamond.2010.11.012

24. Fujimoto Y and Saito S. Energetics and electronic structures of pyridine-type defects in nitrogen-doped carbon nanotubes. Physica E: Low-dimensional Systems and Nanostructures. 2011; 43:677-680. http://dx.doi.org/10.1016/j. physe.2010.07.027

25. Jana D, Chen L-C, Chen CW and Chen K-H. An ab-initio approach to the optical properties of $\mathrm{CxNy}$ single wall nanotubes. Diamond and Related Materials. 2009; 18:1002-1005. http://dx.doi.org/10.1016/j.diamond.2009.02.020

26. Wei J, Zeng H, Zhou Z, Yang W and Peng P. Effects of nitrogen substitutional doping on the electronic transport of carbon nantoube. Physica E: Lowdimensional Systems and Nanostructures. 2008; 40:462-466. http://dx.doi. org/10.1016/j.physe.2007.06.060

27. Schultz D, Droppa Junior R, Alvarez F and Dos Santos MC. Stability of Small Carbon-Nitride Heterofullerenes. Physical Review Letters. 2003; 90:015501(1-4).

28. Carvalho ACM and Dos Santos MC. Nitrogen-substituted nanotubes and nanojunctions: Conformation and electronic properties. Journal of Applied Physics. 2006; 100:084305-1-084305-5. http://dx.doi.org/10.1063/1.2357646

29. Stewart JJP. Optimization of parameters for semiempirical methods 1. Method Journal of Computational Chemistry. 1989; 10:209-220. http://dx.crossref. org/10.1007\%2Fs00894-007-0233-4
30. Young DC. Computational Chemistry: A practical guide for applying techniques to real-world problems. New York: Wiley-Interscience; 2001. http://dx.doi.org/10.1002/jcc.540141112

31. Schmidt MW, Baldridge KK, Boatz JA, Elbert ST, GordonMS, Jensen JH et al. General atomic and molecular electronic-structure system. Journal of Computational Chemistry. 1993; 14:1347-1363. http://dx.doi.org/10.1002/ jcc.540141112

32. Frisch MJ, Trucks GW, Schlegel HB, Scuseria GE, Robb MA, Cheeseman JR et al. Gaussian 03. Version 6.1. Wallingford: Gaussian, Inc.; 2004.

33. Becke AD. Density-functional exchange-energy approximation with correct asymptotic behavior. Physical Review A. 1988; 38:3098-3100. http://dx.doi org/10.1103/PhysRevA.38.3098

34. Lee C, Yang W and Parr RG. Development of the Colle-Salvetti corretationenergy formula into a functional of the electron density. Physical Review B. 1988; 37:785-789. http://dx.doi.org/10.1103/PhysRevB.37.785

35. Stevens WJ, Basch $\mathrm{H}$ and Krauss M. Compact effective potentials and efficient shared-exponent basis sets for the first- and second-row atoms. Journal of Chemical Physics. 1984; 81:6026-6033. http://dx.doi.org/10.1063/1.447604

36. Carvalho ACM and Dos Santos MC. Stabilizing Y-junctions and ring structures through nitrogen substitution. AIP Conference Proceedings. 2004; 723:347-350. http://dx.doi.org/10.1063/1.1812104

37. Ding P, Liang E, Chao M, Guo X and Zhang J. Synthesis, characterization and low field emission of CNx nantoubes. Physica E: Low-dimensional Systems and Nanostructures. 2005; 25:645-659. http://dx.doi.org/10.1016/j. physe.2004.09.010

38. Dos Santos MC and Alvarez F. Nitrogen substitution of carbon in graphite: Structures evolution toward molecular forms. Physical Review B. 1998 58:13918-13924. http://dx.doi.org/10.1103/PhysRevB.58.13918

39. Czerw R, Terrones M, Charlier J-C, Blase X, Foley B, Kamalakaran R et al. Identification of electron donor states in $\mathrm{N}$-doped carbon nanotubes. Nano Letters. 2001; 1:457-460. http://dx.doi.org/10.1021/n1015549q

40. Ma XC, Wang E, Zhou W, Jefferson DA, Chen J, Deng S et al. Polymerized carbon nanobells and their field-emission properties. Applied Physics Letters. 1999; 75:3105-3107. http://dx.doi.org/10.1063/1.125245

41. Zhong DY, Liu S, Zhang G and Wang EG. Large-scalle well aligned carbon nitride nanotube films: low temperature growth and electron field emission. Journal of Applied Physics. 2002; 89:5939-5943. http://dx.doi. org/10.1063/1.1370114

42. Zhang GY, Ma XC, Zhong DY and Wang EG. Polymerized carbon nitride nanobells. Journal of Applied Physics. 2002; 91:9324-9332. http://dx.doi. org/10.1063/1.1476070

43. Wang XB, Liu Y, Zhu D, Zhang L, Ma H, Yao N et al. Controllable growth, structure, and low field emission of well-aligned $\mathrm{CNx}$ nanotubes. Journal of Physical Chemistry B. 2002; 106:2186-2190. http://dx.doi.org/10.1021/ jp013007r

44. Han J, Anantram MP and Jaffe RL. Observation and modeling of single-wall carbon nanotube bend junctions. Physical Review. B 1998; 57:14983-14989. http://dx.doi.org/10.1103/PhysRevB.57.14983

45. Menon M and Shrivastava D. Carbon nanotube based molecular electronic devices. Journal Materials Research. 1998; 14:2357-2362.

46. Andriotes AN, Menon M, Srivastava D and Chernozatonskii L. Ballistic switching and rectification in single wall carbon nanotube $\mathrm{Y}$ junctions. Applied Physics Letters. 2001; 79:266-268. http://dx.doi.org/10.1063/1.1385194

47. Lim SH, Ruijiang L, Wei J and Jianyi L. Effects of nitrogenation on singlewalled carbon nanotubes within density functional theory. Physical Review. B 2007; 76:195406(1-16). http://dx.doi.org/10.1103/PhysRevB.76.195406

48. Terrones M, Ajayan PM, Banhart F, Blase X, Carroll DL, Charlier JC et al. $\mathrm{N}$-doping and coalescence of carbon nanotubes: synthesis and electronic properties. Applied Physics A: Materials Science \& Processing. 2002; 74 355-361. http://dx.doi.org/10.1007/s003390201278

49. Rocha AR, Rossi M, Fazzio A and Da Silva AJR. Designing real Nanotubebased gás sensors. Physical Review Letters. 2008; 100:176803(1-4). http://dx.doi.org/10.1103/PhysRevLett.100.176803

50. Ghosh P, Subramanian M, Afre RA, Zamri M, Soga T, Jimbo T et al. Growth of Y-junction bamboo-shaped CNx nanotubes on GaAs substrate using single feedstock. Applied Surface Science. 2009; 255:4611-4615. http://dx.doi. org/10.1016/j.apsusc.2008.12.005 